\title{
The Impact of Digitally Enhanced Reading Interventions on Struggling Readers and Teacher Education Candidates
}

\section{Cynthia B. Vavasseur, Fran Crochet, Sara Dempster}

Nicholls State University, Thibodaux, LA, USA

Email: Cynthia.vavasseur@nicholls.edu,Fran.crochet@nicholls.edu, Sara.dempster@nicholls.edu

How to cite this paper: Vavasseur, C.B. Crochet, F. and Dempster, S. (2016) The Impact of Digitally Enhanced Reading Interventions on Struggling Readers and Teacher Education Candidates. Open Journai of Social Sciences, 4, 97-112. http://dx.doi.org/10.4236/jss.2016.411008

Received: October 13, 2016

Accepted: November 22, 2016

Published: November 25, 2016

Copyright $\odot 2016$ by authors and Scientific Research Publishing Inc. This work is licensed under the Creative Commons Attribution International License (CC BY 4.0).

http://creativecommons.org/licenses/by/4.0/ (c) (i) Open Access

\begin{abstract}
The unprecedented growth of digital literacy has sparked new mandates for Colleges of Teacher Education, challenging faculty to find innovative ways to incorporate digital literacies into curriculum. This research project paired candidates with elementary grade students for reading intervention using technology. The results provided rich descriptions of specific characteristics of the intervention which proved to be beneficial. The mixed method embedded design allowed researchers to collect both qualitative and quantitative data to provide insights into the research questions. Qualitative data showed that candidates felt that the inclusion of technology with reading intervention caused a higher level of engagement from students. Furthermore, quantitative data showed the intervention increased the reading achievement of students in the five areas of effective reading instruction.
\end{abstract}

\section{Keywords}

Educational Technology, Reading Intervention, iPads

\section{Introduction}

The foundation of this research project was to provide access to 21 st century technology in the form of iPads to both teacher education candidates and first through fifth grade (1st-5th) struggling readers. Using this technology, teacher education candidates tutored struggling readers in cooperative schools. This project was an effort to improve reading intervention knowledge and skills demonstrated by teacher education candidates as well as increase reading performance for 1 - 5 students. The goal of this research project was twofold: 1) To identify the educational impact on teacher candidates' preparedness to provide digitally enhanced literacy instruction; 2) To identify the effec- 
tiveness of iPad apps used in digitally enhanced literacy intervention for $1-5$ students with reading difficulties. Digital texts have been cited as a primary tool to support struggling readers [1] [2]. In addition, carefully selected applications, when used with reading instruction, have been shown to increase reading focus and aid in comprehension skills such as sequencing, retelling, cause and effect and main idea and details [3]. This research aimed to find a unique way to better prepare prospective teachers to serve as cutting edge innovators in the use of 21 st century learning tools, specifically to enhance reading instruction. The research was funded through a state enhancement grant, and data were collected during the 2014-2015 academic year. The links in the appendix of this article can serve as a resource to other Colleges of Education wishing to implement similar projects.

\section{Purpose Statement}

Reading is a critical skill; therefore, teacher education candidates need to be knowledgeable and prepared to teach in a 21 st century, technology rich, learning environment. The purpose of this research was to provide our prospective candidates with experience in the successful implementation of a digitally enhanced reading instruction and/or intervention with struggling 1 - 5 students.

\section{Research Questions}

- What are the effects on teacher candidates' (knowledge, skills, preparedness for a 21 st century classroom) when using an iPad for reading instruction and/or remediation?

- What are the benefits and concerns when using iPads during digitally enhanced literacy intervention for 1 - 5 students with reading difficulties with regards to teaching, practice, and assessment?

\section{Theoretical Framework}

In 2009 the International Reading Association (IRA), re-named International Literacy Association (ILA) in January of 2015, issued a statement: to become fully literate in today's world, students must become proficient in the new literacies of 21st century technologies [4]. IRA/ILA believes that literacy educators have a responsibility to integrate information and communication technologies (ICT's) into the curriculum to prepare students for the futures they deserve.

iPad technology has been shown to not only engage early readers with rich text and deeper comprehension, but also to assist struggling readers [5] [6]. By providing focused, timely, and relevant technology enhanced reading instruction, teacher education candidates facilitated individualized 21st century reading instruction and/or interventions to students with reading deficiencies in grades $1-5$.

One to one technology initiatives have been implemented in numerous colleges of education across the United States [7]. Central to these initiatives are empirical studies that provide evidence of significantly increased student and teacher engagement and moderate increase in student achievement [8]. As supported by research, the most successful one to one initiatives focus on educational goals which technology can enhance, 
rather than focusing on the technology itself [9]. Focusing on this theory, the study was designed to provide individualized, focused reading remediation instruction that focus on the area of greatest need for each student as identified by the Qualitative Reading Inventory instrument (QRI-5) [10]. Additionally, the current research assisted faculty, candidates, and teachers in staying informed about the new digital technologies. Finally, a timely and relevant online eBook as a source of professional development for candidates and teachers was created.

Many researchers stress that the iPad and similar devices are the future of one to one education [7] [11] [12] [13]. iPads were chosen because of the ability of this type of technology to promote anytime, anywhere learning [14]. The iPad allowed both teacher education candidates and 1 - 5 students access to electronic books and the ability to physically interact and manipulate texts according to the student's needs and interest [15]. In addition, applications on the iPad allowed candidates and students to individualize instruction, therefore making the intervention interactive and engaging [1].

IRA states new teachers should be prepared to instruct with technology (2009). The use of technology implemented on a routine basis with active engagement is believed to enhance learning [16]. Technology allows animation in practicing the five components of effective teaching outlined by the National Reading Panel in 2000 [17]. As outlined by the reference [18], five of the areas are: phonemic awareness, phonics, vocabulary, fluency, and comprehension. Writing was added as a sixth essential component. "Writing is an important part of the literacy process. Reading and writing have a reciprocal relationship-one is used to learn and enrich the other and vice versa. As a writer, the reader has a more intimate knowledge of the writing process, allowing her to have a greater connection to another author's text. Writing also supports reading comprehension and recall." [18]. Consequently, for the purpose of this study writing is included as a sixth component.

According to references [19] [20] [21], digital texts are advantageous in supporting the readers' comprehension and engaging individuals that struggle with reading. The iPad allows students more individualized, interactive and engaging interventions through the use of interactive digital texts and applications [1] [3]. The iPad enables the candidates to chart 1 - 5 students' progress, and many of the apps will provide voice activated responses indicating student performance. Furthermore, this research aimed to allow increased access to 21 st century technology as tools for learning to struggling 1 5 reading students [16].

\section{Methodology}

Through a state enhancement grant, $30 \mathrm{iPad}$ Airs were purchased with protective cases. An electronic Candidate Handbook was created and published through iBooks that described the purpose of the project, the apps that would be used initially, and the requirements of the candidates during the project. Candidates enrolled in two reading intervention courses over the course of two academic semesters served as the participants in the study. Classroom teachers identified at risk students in the area of reading 
and recommended them for the digitally enhanced reading intervention project. Candidates administered the Qualitative Reading Inventory-5 (QRI-5) as a pre-assessment to determine one or more of the six areas to focus on with the struggling reader [10]. (This instrument assesses students in the six areas of reading capabilities. Apps in the electronic Candidate Handbook were categorized by these six identified areas. Candidates selected the apps, designed instruction for students, and provided time for practice utilizing the apps over fifteen weeks each semester. Candidates were also required to complete an app reflection and analysis, overall project reflection, case report, and interactive eBook (see Appendix 1).

The research was built around a teacher education program at a regional University in the South. Teacher education candidates were enrolled in either a junior or senior level reading course. The first course, Reading Instruction in the Elementary School, is a junior level course that requires candidates to implement effective reading practices in a supervised partner school classroom. The theory and practice for the effective development of reading abilities among elementary grade students is demonstrated via individual, small group, and whole class field experiences. The second course, Clinical Analysis of Reading Difficulties, is a senior level course in which candidates work oneon-one with an elementary grade student on the college campus in an after school supervised tutoring program. Candidates are required to effectively use techniques and procedures, methods and materials for analyzing and correcting reading disabilities.

Nineteen teacher education candidates participated in the study. Participants in this study were chosen because of their area of concentration (grades 1 - 5 education) and enrollment in specific reading intervention courses. The candidates worked with students in the local public school systems in grades first through fifth. The students who received remediation were all identified by their classroom teacher as performing below grade level in reading and/or struggling with reading. There were a total of nine male students ranging in ages six through ten and a total of eight female students ranging in ages six through eleven. One male was identified as a special education student, while one female was identified with Attention Deficit Hyperactive Disorder. One male was a repeater and still performing below grade level expectancy. While the tutoring of struggling readers by teacher education candidates was an ongoing focus of the two identified courses, this research focused on the implementation of targeted instruction and/or intervention using digitally enhanced intervention strategies from one or more of the six components of effective teaching. The project strove to improve reading instruction and/or intervention skills in teacher education candidates and therefore improve reading proficiency in struggling 1 - 5 readers. The Teacher Education department wishes to serve as a cutting edge innovator concerning the use of 21 st century learning tools and reading intervention strategies.

Data were collected through a mixed method embedded design, collecting qualitative and quantitative data simultaneously and analyzing the data points at different stages during the research [22]. Both types of data were used to provide a better understanding of the research questions. Data collection encompassed candidates' pre and post 
QRI-5 reports on individual at risk students, an app reflection and analysis, and overall project reflection. The quantitative data from the QRI-5 pretest was to provide a baseline and identify the student's area of remediation and intervention, the quantitative data from the QRI-5 posttest served as a possible justification for the qualitative data results and to determine growth. The qualitative data were collected over two academic semesters in an effort to study themes displayed during structured instruction and/or intervention. After data were collected, a thematic analysis was used to identify recurring themes in order to provide a rich description of effects on teacher candidates and benefits to 1 - 5 students.

\section{Data Collection}

With the above research questions framing the project implementation, data were collected during instruction and/or interventions that took place during the 2014-2015 academic year. Quantitative data were collected twice using the QRI-5instrument each semester. At the beginning of the semester when candidates completed an Initial QRI-5 Report indicating a 1 - 5 student's independent, instructional, and frustration reading levels. Following intervention with 21st century technology tools throughout the semester, the QRI 5 was re-administered and student's independent, instructional, and frustration reading levels were identified and compared.

Qualitative data were collected through four sources. One source required candidates to complete a detailed app rating chart on a minimum of ten tutoring sessions when an App was utilized. Candidates described specific strengths and weaknesses of the iPad and app in meeting the needs of their individual student. The app, area of concentration with pre and post application, and student's comments were included. Another source, reflective journal entry, required the candidate to reflect on his or her lesson implementation and identify any necessary curricular revisions which included the use of the iPad and apps on a minimum of ten of their lessons. The third qualitative data collection source was a section of the Final QRI-5Report which required the candidate to identify the usefulness of apps included in the intervention process. Finally, candidates completed an Overall Candidate Project Reflection Questionnaire, which asked open ended questions about a candidate's thoughts on individual aspects of the project.

\section{Data Analysis}

Qualitative data were analyzed through constant comparative analysis [23]. Using this method, unstructured text data obtained by transcribing open ended responses to questions and discussion prompts were segmented and coded according to significant themes and patterns. As outlined by reference [22], raw data were formed into indicators and grouped into codes. These indicators and codes were constantly compared to eliminate redundancy. Through constant comparative analysis, app rating charts, journal entries, reports and questionnaires were examined to identify categories, to create sharp distinctions between categories and to decide which categories were theoretically significant [24]. From this analysis, thick description of the themes and categories were developed to illustrate the findings of the study. In addition, quantitative data were collected through a pre and post test. The QRI-5 instrument, an informal reading inven- 
tory, was administered to obtain information for the researcher that assisted in the design of the intervention. This instrument was given again following the intervention. In order to determine if there was a significant growth in the reading abilities of the student, a dependent samples $t$ test was performed.

\section{Results}

The research questions were divided into two major areas: candidate reflection on the use fullness of the technology for the overall learning of the student, and student achievement and engagement in the intervention. Data analysis and results are described below according to research questions and emerging themes.

\section{1) Data Analysis}

Table 1 displays the sources of data used in answering each research question.

The purpose of this research was to provide candidates with experience in the successful implementation of digitally enhanced reading instruction and/or intervention with struggling 1 - 5 students. The first goal of this research was to develop an understanding of the effects on teacher candidates' preparedness for a $21^{\text {st }}$ century classroom when using an iPad for reading instruction. Insights gained from the content analysis of the data produced three distinctions in using the iPad for intervention: (a) using the iPad to provide instruction, or teach, (b) using the iPad for student practice of a skill, and (c) using the iPad for evaluation of the student's competency of a specific reading skill. Table 2 refers to the ways iPads could be used to enhance reading instruction.

The collected data indicated:

The following apps were the only ones identified by the candidates as being used to provide instruction in a literacy concept: iStory Time, Word Wizard, Sequencing, Sentence Builder, and ABC Pocket Phonics. The app iStory Time was noted as being helpful to "read Madagascar and model how a fluent reader sounds. "The app Word Wizard

Table 1. Research questions and data sources.

\begin{tabular}{cc}
\hline Research question & Source of data analysis \\
\hline What are the effects on teacher candidates' & Overall project reflection \\
(knowledge, skills, preparedness for a 21st century classroom) & App reflections \\
when using an iPad for reading instruction and/or remediation? & Reflective journal entry \\
QRI5 final report \\
What are the benefits and concerns when using iPads during & Overall project reflection \\
digitally enhanced literacy intervention for K-5 students with & App reflection \\
reading difficulties with regards to teaching, practice, and assessment? & QRI5 pre and post scores \\
\hline
\end{tabular}

Table 2. iPad use definitions.

iPad for instruction

iPad for student practice

iPad for evaluation
Teaching and modeling of a skill or concept by the candidate.

Drill and practice by student to ensure competency. by the student to determine proficiency and mastery. 
was also used "to teach words in the story that were unfamiliar to the student. It was beneficial because they learned them." The candidates identified the Sequencing app as a teaching tool and stated "The app was useful in showing the student how to put things in order." It was also determined that Sentence Builder, "was a very useful app in showing how to properly write a sentence and the parts of a sentence."

Using the iPad and apps to provide practice for the students was utilized with almost every app. The games were a huge motivating success and provided much needed drill and repetition. The comments were quite extensive in regard to practice. Following area few of the comments written. As noted by a candidate, "Opposites provided great practice for the student." Another candidate wrote, "I used iWrite Words which provided great practice for the student." The One Minute Reader app was identified as, "greatfor working on fluency skills."

The use of the apps for assessment practices as per identified by the candidates was very limited. They only indicated Quizlet and the Fluency apps as being used for assessment purposes; however, these apps were identified by numerous candidates. The Fluency App, 5th Reading, "was useful and tested the students' ability to read fluently." The app Quizlet, "was used to flash sight words to the student during assessments. This app is useful because it saves on paper, and the student preferred to look at the iPad than a sheet of paper."

The aggregated data indicates that the limited use of apps for instruction was appropriate, due to the lack of instruction and explanation provided by the apps. Consequently, the apps were appropriately used for practice and review. The candidates' recognition of the fact that a thorough explanation and modeling of the skill was best practice before a student attempts to drill and practice the skill was key. It was also determined that there were more opportunities which the candidates could have utilized the apps for more assessment purposes than they did. The app Google Doc/Drive could have easily been utilized to create individualized assessments on the needs of the student. Candidate expertise in this area needs further development.

The second goal of the research was to develop an understanding of the benefits and drawbacks, as perceived by 1 - 5 students and candidates of the inclusion of the iPad in the remediation program. A summary of the benefits and challenges as perceived by candidates can be found Table 3.

\section{2) Student Motivation}

Student motivation when using technology is an often debated construct [25] [26]. This phenomenon was also observed during the study. A major benefit of the project, as perceived by the candidates, was student motivation during the tutoring session when using the iPads. "iPads are cooler than a dry erase board." It was noted that many of the 1 - 5 students who were participating in the study were from low socioeconomic status families, and often did not have this type of technology available to them at home. This caused students to look forward to coming to tutoring sessions, and caused students to be highly motivated and on task during tutoring sessions. "I like using the iPad because nobody else is getting to use it." The technology also provided opportune- 
Table 3. Benefits and drawbacks of intervention.

\begin{tabular}{|c|c|}
\hline Benefits & Challenges \\
\hline 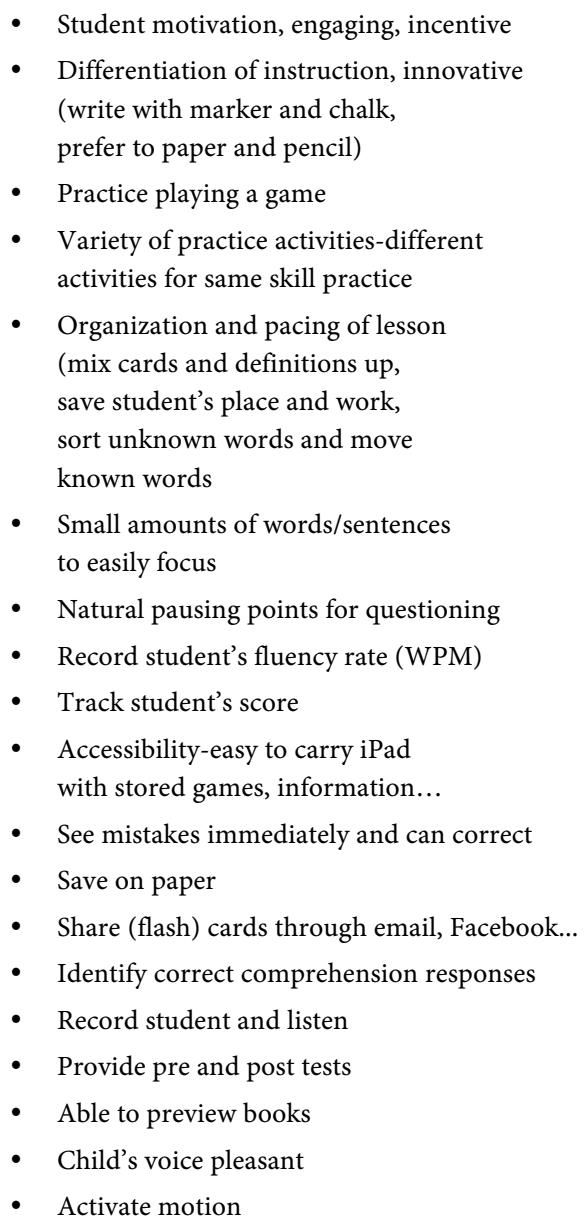 & 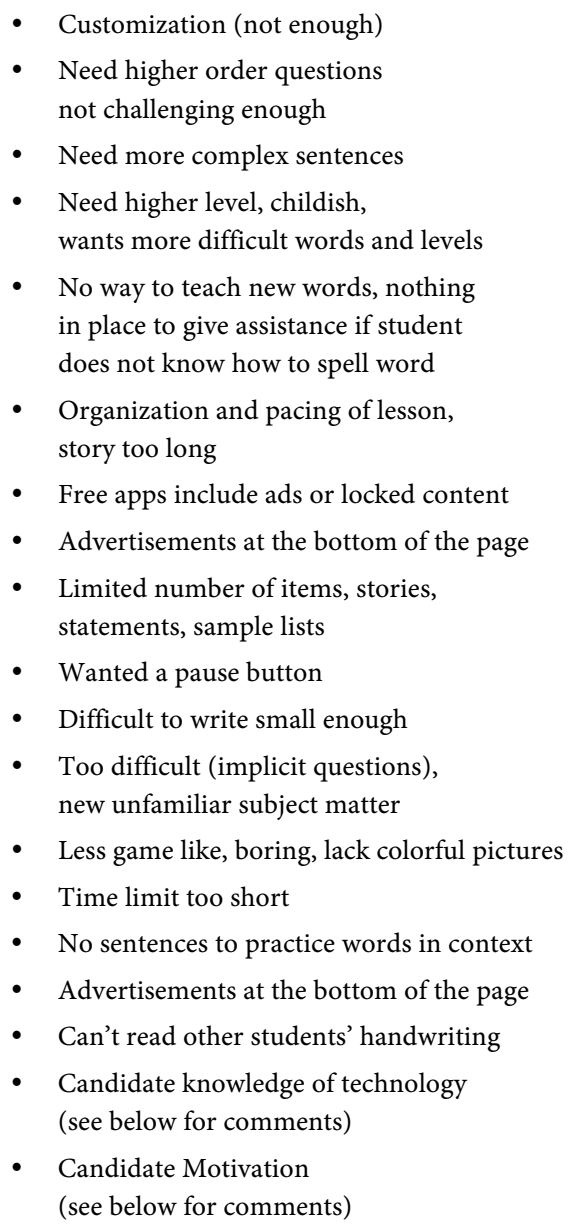 \\
\hline
\end{tabular}

ties for students with a kinesthetic learning style to be engaged. Many of the apps used called for students to "get up and shake" when a goal was achieved. "Mary loved this app because she got to shake the iPad and get out of her seat"

\section{3) Differentiation of Instruction}

When choosing apps to use in the program, the researchers specifically chose apps with documented success [27] [28] [29]. As a result, many candidates noted how the differentiation of instruction within the apps was a major benefit of the project. For example, different "levels" could be chosen on many of the apps. "It was very useful that we could adjust levels within the app and choose what kind of questions it would ask the student."

\section{4) Immediate Feedback}

The availability of immediate feedback was another benefit of using the apps to provide instruction. Many of the apps had built in "levels" that students could complete and master, before going on to a higher level. In addition, the technology provided immediate feedback in the form of the student's own voice. “This was my student's favo- 
rite by far. She loved listening to herself read and give herself meaningful feedback." By listening to her own voice reading, the student herself identified areas of deficiency.

\section{5) Accessibility}

The researchers' code of 'accessibility' manifested in two different types of accessibility.

First, candidates identified characteristics of assistive technology that influenced the student in a positive nature. "Alyssa liked using the Ipad to read because I was able to increase the font size to help her see more clearly when she read what she wrote." Second, candidates were very impressed by the availability of materials within the apps themselves: "It (the app) is very helpful because there are a lot of free fables all at different grade levels for students to read." Other apps went beyond one specific genre: "The app allows you to search and get books of all types of genres."

\section{6) Challenges of the Project}

\section{Organization and Pacing of the Lesson}

In contrast to the positive comments about organization and pacing of the lesson noted above, candidates also showed frustration with the same theme: "The student really liked this app. He went through each level quickly and was upset when he realized that it was the same statements that he had previously. He did continue to play, but it was no longer fun. He knew each answer and was no longer being challenged." The fact that the app was linear and unable to be changed caused the student's motivation to fall. "The availability of complete apps would be more helpful as well, once a student has completed the levels they need to have the next level available to them on apps that have been effective." Another candidate stated," I did find that some of the apps were hard to relate to older grades because most of the apps were for younger students." In addition, the set examples and lack of ability to customize examples also were seen as a problem. "The student enjoyed this activity, but some of the sequences confused him. For example, one sequence showed a boy holding toothpaste and then a boy holding a toothbrush and toothpaste. The student was unable to perceive these slight changes between the two scenes." Several candidates noted that the iPad functioned well when working with one student but felt it would be difficult when teaching a group or whole class. "Having the iPad as an option is very helpful when working one on one with a student... one person using the iPad can cause a disruption in the class" Another candidate stated: "It was best used one on one with a student unless all students in the group are given one." A challenge dictated by the course requirements was noted by a candidate, "There was a certain amount of apps that needed to be used in my course. This sometimes caused the lesson not to as great as it could be."

\section{Candidate Knowledge of Technology}

Candidates' lack of confidence navigating the iPad interface results in a lack of confidence using the reading apps. Candidates who are lacking in confidence using the iPad also lack the skill to solve small issues that come up through a lesson using the iPad. This may cause candidates to have negative opinions about using specific apps and using the iPads in general. 


\section{Candidate Motivation}

Candidates lack the motivation to utilize the iPads to the full intended extent. Ideally, candidates would explore the apps available to them and then research more apps they could use during lessons. Candidates should find additional apps that fit the needs of their student and other apps that could supplement the apps in place. Candidates are able to provide many negative comments about the apps (specific comments below),but are unable to provide suggestions for apps that do fit the needs of his or her student. Rather than continue use of apps they feel are not sufficient, candidates should research and find apps that can make up for those that are lacking.

Candidate negative comments about apps that support "lack of knowledge" and "lack of motivation".

In addition, quantitative data was analyzed at the conclusion of the study. The researchers coded and analyzed the quantitative data and entered it into the SPSS program. The data were cleaned to ensure that unusual data did not exist. Descriptive and inferential statistical procedures were used to analyze the QRI5 survey data. It was concluded that although not statistically significant at the 0.05 level, mean scores did improve from an average of 5.5 to 6.1. Struggling readers who participated in the project showed achievement growth when comparing pre and post test scores.

\section{Discussion}

Although the traditional one on one type of interventions have shown to increase aptitude for struggling readers [29] [30], this study shows that technology assisted reading intervention provided additional benefits during one on one sessions with struggling readers. Preservice teachers and 1 - 5 students reflected on how the apps allow for the differentiation of instruction during intervention. This finding adds to the work by reference [31] that suggests that when students feel that they are more in control of the learning, greater benefits may be seen.

Similarly, researchers found that the apps allowed for a structured and organized pacing of the lesson, which may have also led to a greater sense of control. This finding supports the findings of the case study performed by reference [4], which found that giving a struggling reader a sense of being in control of his learning may facilitate reading growth and achievement. The final major benefit noted by both candidates and students is the accessibility of reading instructional materials and books within the iPad. Apps and eBooks allowed candidates and students accessibility to many tools used within and outside of the tutoring lessons.

This study also found many of the same struggles of using iPads during reading interventions as those found by Hutchinson, Beschorner \& Schmidt Crawford [3]. Specifically, the manipulation, or specific customization of specific apps or features within the apps are highly limited. It was seen that many times the candidates and/or students wanted to ask higher order thinking questions, or manipulate the organization or pacing of an app or feature within an app, but were unable to. Reference [32] found both internal and external barriers for success of an iPad program. 
Although this project did not see many of the external barriers such as application acquisition or connectivity, similar external challenges in the areas of candidate motivation, self-efficacy and skill level were seen [32]. Many studies have shown that iPads allow for differentiated instruction and practice that increase students' motivation in reading instruction [1] [14] [15]. This intervention showed three distinct ways that the iPads were used during instruction, and candidate reflection on their use in these different ways. More research is needed on the distinctions of iPads being used for instruction, evaluation and practice, and the effectiveness of each. Knowing this, the importance of utilizing the technology with purpose, aligned to specific learning goals must be highlighted.

\section{Conclusion}

The Technology Assisted Reading Intervention Program provided a framework for best practices when using iPads with struggling readers. Benefits and challenges were noted by both candidates, and 1 - 5 student that aligned with the research of Northrop \& Killeen [33]. Both studies concluded that ipads can offer unique ways for students to practice early literacy concepts, and pre service candidates to teach and assess early literacy concepts [33]. However, it was determined by the candidates that the iPad and apps were beneficial for student practice; however, they lacked the instructional qualities needed to remediate the students. The need for teacher instruction and modeling remains a critical component of good teaching when working with students exhibiting reading difficulties. Limitations of this study include a small sample size and limited time frame of technology assisted reading interventions. Considerations for future projects include working in other content areas and working with special education courses. Although increased motivation when working with the ipads was seen overall, further research was needed on student time on task when engaged in a digitally enhanced reading intervention.

\section{Acknowledgements}

The researchers would like to thank Ms. Megan Luke, Ms. Brooke Mezac, Ms. Alexis Guedry and Ms. Kailie LeBlanc for their assistance during this research.

\section{References}

[1] Larson, L.C. (2010) Digital Readers: The Next Chapter in eBook Reading and Response. The Reading Teacher, 64, 15-22. http://dx.doi.org/10.1598/RT.64.1.2

[2] Reinking, D. (2001) Multimedia and Engaged Reading in a Digital World. In: Verhoeven, L. and Snow, K., Eds., Literacy and Motivation: Reading Engagement in Individuals and Groups, Erlbaum, Mahwah, 195-221.

[3] Hutchison, A., Beschorner, B. and SchmidtCrawford, D. (2012) Exploring the Use of the iPad for Literacy Learning. Reading Teacher, 66, 15-23. http://dx.doi.org/10.1002/TRTR.01090

[4] Journals. International Literacy Association. (n.d.) https://www.literacyworldwide.org/get-resources/journals 
[5] McClanahan, B., Williams, K., Kennedy, E. and Tate, S. (2012) A Breakthrough for Josh: How Use of an iPad Facilitated Reading Improvement. TechTrends, 56, 20-28. http://dx.doi.org/10.1007/s11528-012-0572-6

[6] McCrea, B. (2010) Measuring the iPad's Potential for Education. THE Journal. http://thejournal.com/articles/2010/01/27/measuringtheipadspotentialforeducation.aspx

[7] DeBacker, T. and Cullen, T. (2014) Attitudes toward and Use of iPads in a College of Education One-to-One Program. In: Searson, M. and Ochoa, M., Eds., Proceedings of Society for Information Technology \& Teacher Education International Conference, Association for the Advancement of Computing in Education (AACE), Chesapeake, 2767-2775.

[8] Bebell, D. and O’Dwyer, L.M. (2010) Educational Outcomes and Research from 1:1 Computing Settings. Journal of Technology, Learning, and Assessment, 9, 5-13. http://www.jtla.org

[9] Corn, J.O. (2013) 1:1 Model Research-National and State Perspectives. The William \& Ida Friday Institute for Educational Innovation.

http://s3.amazonaws.com/mooc-ed.org/course readings/DLT+1-1+Research+Summary.pd f

[10] Leslie, L. and Caldwell, J. (2010) Qualitative Reading Inventory-5. Allyn \& Bacon, Boston.

[11] Allen, R. (2011) Can Mobile Devices Transform Education. Education Update, 53, 2-7.

[12] Ferriter, W. (2010) Ereaders: Get Ready for the Revolution. Educational Leadership, 68, 8485.

[13] Ludlow, B. (2010) The Future of Reading. Teaching Exceptional Children, 43, 4.

[14] Brand, J. and Kinash, S. (2010) Pedagogy: A Quasi Experimental and Ethnographic Pilot Test of the iPad in a Blended Mobile Learning Environment. 27 th Annual Conference of the Australian Society for Computers in Learning in Tertiary Education (ASCILITE), Sydney, 147-151. http://epublications.bond.edu.au/cgi/viewcontent.cgi? article $=1015 \&$ context $=$ tls

[15] Eagleton, M.B. and Dobler, E. (2007) Reading the Web: Strategies for Internet Inquiry. Guilford, New York.

[16] Edutopia Team (2008) Why Integrate Technology into the Curriculum? The Reasons Are Many.

[17] The Knowledge Loom (2008) Professional Development.

[18] The National Reading Panel: Five Components of Reading Instruction, Frequently Asked Questions. (n.d.). http://www.scsk12.org/scs/subject-areas/kweb/images/nationalreadingpanel faq.pdf

[19] Leu, D.J. and Reinking, D. (1996) Bringing Insights from Reading Research to Research on Electronic Learning Environments. In: van Oostendorp, H., Ed., Cognitive Aspects of Electronic Text Processing, Ablex, Norwood, 43-75.

[20] Reinking, D. (1992) Differences between Electronic and Printed Texts: An Agenda for Research. Journal of Educational Multimedia and Hypermedia, 1, 11-24.

[21] Reinking, D. and Watkins, J. (1998) Balancing Change and Understanding in Literacy Research through Formative Experiments. In: Shanahan, T. and Rodriquez-Brown, F., Eds., 47 th Yearbook of the National Reading Conference, National Reading Conference, Chicago, 461-471.

[22] Creswell, J. (2002) Educational Research. Pearson Education, Upper Saddle River.

[23] Glaser, B.G. and Strauss, A.L. (1967) Discovery of Grounded Theory: Strategies for Qualitative Research. Aldine Publications, Chicago. 
[24] Gall, M.D., Borg, W.R. and Gall, J.P. (1996) Educational Research: An Introduction. Longman, Hite Plains.

[25] Granito, M. and Chernobilsky, E. (2012) The Effect of Technology on a Student's Motivation and Knowledge Retention. NERA Conference Proceedings 2012 Paper 17.

[26] Linnenbrink, E. and Pintrich, P. (2003) The Role of Self Efficacy Beliefs in Student Engagement and Learning in the Classroom. Reading \& Writing Quarterly, 19, 119-137. http://dx.doi.org/10.1080/10573560308223

[27] Hutchison, A. and Woodward, L. (2014) A Planning Cycle for Integrating Digital Technology into Literacy Instruction. The Reading Teacher, 67, 455-464. http://dx.doi.org/10.1002/trtr.1225

[28] Hutchison, A. and Beschorner, B. (2014) Using the iPad as a Tool to Support Literacy Instruction. Technology, Pedagogy and Education, 24, 407-422. http://dx.doi.org/10.1080/1475939X.2014.918561

[29] Mallette, M.H. and Barone, D. (2014) Interesting Ways to Use iPads in the Classroom. The Reading Teacher, 67, 621-625. http://dx.doi.org/10.1002/trtr.1264

[30] Nowacek, E.J. and Mamlin, N. (2007) General Education Teachers and Students with ADHD: What Modifications Are Made? Preventing School Failure, 51, 28-35. http://dx.doi.org/10.3200/PSFL.51.3.28-35

[31] Newton, J.S., Ard Jr., W.R. and Horner, R.H. (1993) Validating Predicted Activity Preferences of Individuals with Severe Disabilities. Journal of Applied Behavior Analysis, 26, 239-245. http://dx.doi.org/10.1901/jaba.1993.26-239

[32] Lana, M. and Janice, A. (2015) Teacher Self Efficacy in 1:1 iPad Integration in Middle School Science and Math Classrooms. Contemporary Issues in Technology and Teacher Education (CITE Journal), 15, 334-367.

[33] Northrop, L. and Killeen, E. (2013) A Framework for Using iPads to Build Early Literacy Skills. Reading Teacher, 66, 531-537. http://dx.doi.org/10.1002/TRTR.1155 


\section{Appendix 1: Overall Candidate Project Reflection}

Final Case Study Report_(90 points)

Student:

Birth date: Clinician: Your name

Chronological Age: years and months (1)

Present date-birth date

School:

Grade Placement:

Estimated Reading Instructional Level: based on findings of the QRI (4)

Instructor: Dr. Fran G. Crochet

I. Background Information: (2)

\section{Evaluation Measures:}

1) The Qualitative Reading Inventory

The Qualitative Reading Inventory has graded word lists and passages, which the child reads individually to the teacher. The child's independent reading level, instructional reading level, frustration level and listening capacity level are determined after evaluating performance when reading orally and silently and after material is read aloud by the tutor.

Copy from initial assessment report

\begin{tabular}{|c|c|c|}
\hline Dates of Assessments & Initial: & Final: \\
\hline \multicolumn{3}{|l|}{ Word Lists: (2) } \\
\hline \multicolumn{3}{|l|}{ Independent Level } \\
\hline \multicolumn{3}{|l|}{ Word Lists: (2) } \\
\hline \multicolumn{3}{|l|}{ Instructional Level } \\
\hline \multicolumn{3}{|l|}{ Word Lists: (2) } \\
\hline \multicolumn{3}{|l|}{ Frustration Level } \\
\hline $\begin{array}{l}\text { Results of Analogy Test (6): } \\
\text { PP1 }\end{array}$ & $\begin{array}{l}\text { High Frequency Words score- } \\
\text { Low Frequency Words score- }\end{array}$ & $\begin{array}{l}\text { High Frequency Words score- } \\
\text { Low Frequency Words score- }\end{array}$ \\
\hline $\begin{array}{c}\text { Results of Analogy Test: } \\
\text { PP } 2 / 3\end{array}$ & $\begin{array}{l}\text { High Frequency Words score- } \\
\text { Low Frequency Words score- }\end{array}$ & $\begin{array}{l}\text { High Frequency Words score- } \\
\text { Low Frequency Words score- }\end{array}$ \\
\hline $\begin{array}{c}\text { Results of Analogy Test } \\
\text { Primer }\end{array}$ & $\begin{array}{l}\text { High Frequency Words score- } \\
\text { Low Frequency Words score- }\end{array}$ & $\begin{array}{l}\text { High Frequency Words score- } \\
\text { Low Frequency Words score- }\end{array}$ \\
\hline $\begin{array}{c}\text { Results of Analogy Test: } \\
\text { First }\end{array}$ & $\begin{array}{l}\text { High Frequency Words score- } \\
\text { Low Frequency Words score- }\end{array}$ & $\begin{array}{l}\text { High Frequency Words score- } \\
\text { Low Frequency Words score- }\end{array}$ \\
\hline
\end{tabular}

QRI Comments: COMMENTS ABOUT CHILD'S PERFORMANCE DURING

ASSESSMENT, attach all word lists, report and discuss the child's graded word list levels and behaviors (5)

Results of Passages: (Identify by level-Pre-Primer, First, Second...) 


\begin{tabular}{|c|c|c|}
\hline Oral Reading & Initial & Final \\
\hline Overall Passage (2): & Narrative & Narrative \\
\hline Independent Level & Expository & Expository \\
\hline Overall Passage (2): & Narrative & Narrative \\
\hline Instructional Level & Expository & Expository \\
\hline Overall Passage (2): & Narrative & Narrative \\
\hline Frustration Level & Expository & Expository \\
\hline Silent Reading If Applicable & Initial & Final \\
\hline Overall Passage (2): & Narrative & Narrative \\
\hline Independent Level & Expository & Expository \\
\hline Overall Passage (2): & Narrative & Narrative \\
\hline Instructional Level & Expository & Expository \\
\hline Overall Passage (2): & Narrative & Narrative \\
\hline Frustration Level & Expository & Expository \\
\hline Listening Capacity If Applicable & Initial & Final \\
\hline Overall Passage: & Narrative & Narrative \\
\hline Independent Level & Expository & Expository \\
\hline Overall Passage: & Narrative & Narrative \\
\hline Instructional Level & Expository & Expository \\
\hline Overall Passage: & Narrative & Narrative \\
\hline Frustration Level & Expository & Expository \\
\hline
\end{tabular}

\section{Comments: COMMENTS ABOUT CHILD'S PERFORMANCE DURING}

ASSESSMENT, compare word list scores to comprehension scores

Attach all passages scored.

Report and discuss the child's oral reading levels, types of passages, titles of passages, behaviors, etc. (5).

\section{2) Oral Reading Comprehension}

Satisfactory only (performance compared to grade level placement).

Unsatisfactory.

Narrative text comprehension out performed expository text comprehension.

Expository text comprehension out performed narrative text comprehension.

Familiar text aided comprehension in comparison to unfamiliar text.

Retelling Performance was satisfactory.

Retelling Performance was unsatisfactory (5).

III. Interventions Used: Identify App, Usefulness, Adaptations If Any (12)
a) Phonemic Awareness
b) Phonics-
c) Vocabulary
d) Fluency-
e) Comprehension
f) Writing 


\section{Summary, Recommendations (10)}

(Summarize findings and provide a minimum of three legitimate interventions or approaches that you would recommend that the student continue to use or new interventions that you would recommend. The three interventions should be technology based. (Consult with EDUC 251 candidates and recommended resources on syllabus for assistance.) Give a rationalization for each.) Look at what has been accomplished, growth and performance and areas still needing remediation: word list score, familiarity with text, retelling, explicit questions, implicit questions, reading habits, miscue analysis sheets, etc.

Grammar, Punctuation, etc.: 5 points.

Scoring Correctly: 8 points.

Accurate Information and conclusions: 5 point.

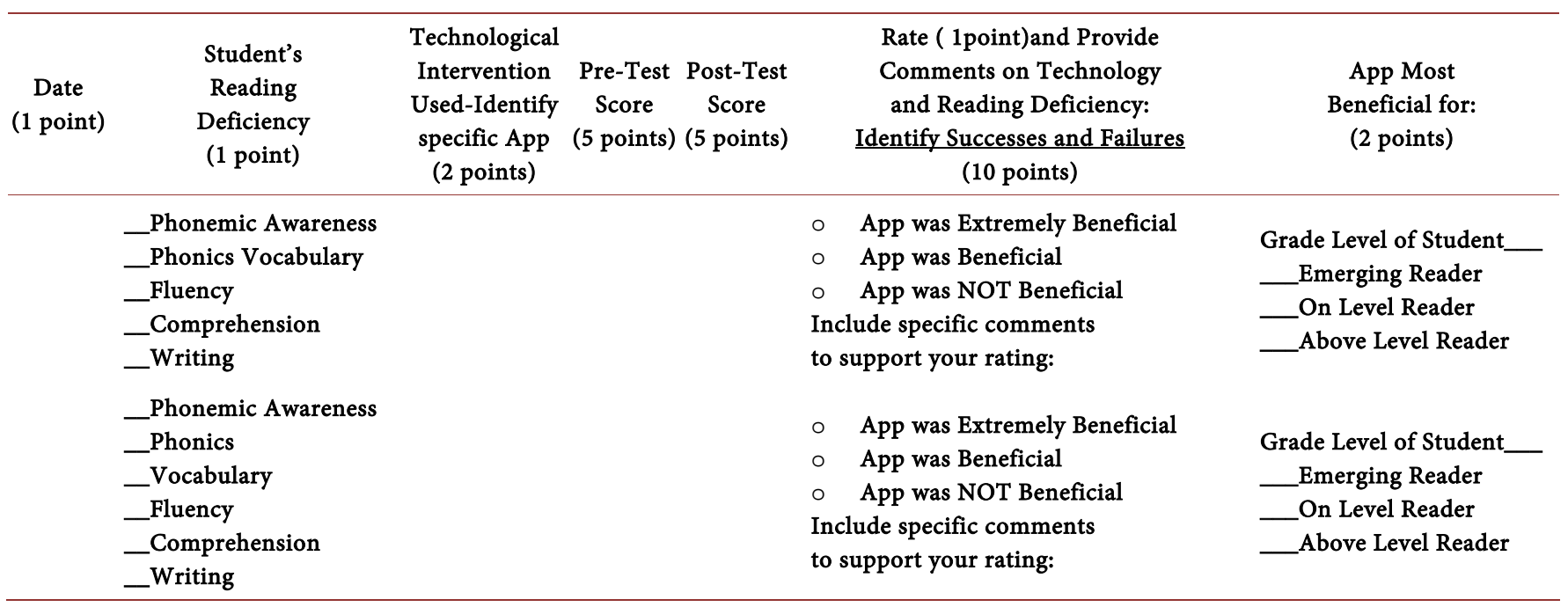

\section{Focus Group Questions}

1) Strengths in using ipads for reading intervention instruction, student performance, student engagement.

2) Weakness of the ipad for reading intervention instruction, student performance, student engagement.

3) Suggestions for improvements. 
Submit or recommend next manuscript to SCIRP and we will provide best service for you:

Accepting pre-submission inquiries through Email, Facebook, LinkedIn, Twitter, etc. A wide selection of journals (inclusive of 9 subjects, more than 200 journals)

Providing 24-hour high-quality service

User-friendly online submission system

Fair and swift peer-review system

Efficient typesetting and proofreading procedure

Display of the result of downloads and visits, as well as the number of cited articles

Maximum dissemination of your research work

Submit your manuscript at: http://papersubmission.scirp.org/

Orcontact jss@scirp.org 